\title{
Improving Classroom Engagement to Maximize Learning in an Interdisciplinary Dual Faculty Capstone Experience at the University of Manitoba
}

\author{
W.C.D. DeGagne* and Paul E. Labossiere, \\ Faculty of Engineering, University of Manitoba, Winnipeg. MB, Canada R3T 5V6 \\ *William.degagne@umanitoba.ca \\ Paul.Labosiere@umanitoba.ca
}

\begin{abstract}
-
One of the most effective and efficient ways for an engineering program to facilitate compliance with the Canadian Engineering Accreditation Board (CEAB) accreditation criteria is through capstone design projects and courses [2]. Currently, The University of Manitoba Faculty of Engineering has several capstone design courses; however, each is independently focused on its own respective discipline. The resulting educational experience for students, though rigorous and challenging, is maintained within the boundaries of the students' engineering discipline, thereby neglecting to provide the opportunity for students to work with people from multiple disciplines and across different faculties. This method of education, where students work in isolation, arguably does not reflect real world engineering. Through internal focus group meetings, program representatives from the Faculty of Engineering at The University of Manitoba agree that the capstones should be more reflective of real life situations. Interdisciplinary courses are most important because they "...articulate the difference between educational problems and workplace problems" [1]. Hence, to allow "(students) persons from different disciplines to work collaboratively and are integrated to combine their knowledge to solve a problem" (sic)[4], interdisciplinary capstone courses are essential to a rounded engineering education. Furthermore, teaming with the Faculty of Architecture will provide several benefits for both facilities such as: develop lifelong learning patterns; foster cooperative and collaborative team relationships; and, allow both facilities to learn the other's cultures and technical languages.
\end{abstract}

Since 2016, The University of Manitoba has presented research papers at the Canadian Engineering and Education Association (CEEA) conferences on the development and future assessment of an interdisciplinary capstone course. These papers have shown the evolution of the course from a multidisciplinary engineering program to an interdisciplinary Engineering and Architectural dual faculty offering. The course was launched in January, 2018, and will be evaluated through the winter session and into the fall.

This paper, will explore, define, and explain how the proposed new engineering/architecture interdisciplinary capstone and dual faculty course will be developed, highlight the early stages of its initiation, describe the ongoing implementation, outline how the performance of the new course will be evaluated, delve into how the new course will be improved to make it more meaningful and practical to both faculties and students, and; discover how engagement can improved student learning.

Keywords: Interdisciplinary; capstone course, Metacognition, Level of Consciousness, student engagement, dual faculty.

\section{INTRODUCTION}

From recent literature research into understanding levels of consciousness (LOC), it was discovered that outside of medicine, there has been limited investigations conducted on whether LOC could be used to influence higher learning, and student engagement, particularly in interdisciplinary capstone courses. Level of consciousness is a measure of a person's arousability and responsiveness to stimuli from the environment, [3]. As an extension and further assessment of the interdisciplinary dual faculty experience, this paper will examine whether a student's classroom engagement could be defined as a starting point to maximize learning in an interdisciplinary/dual faculty learning environment. Engagement and metacognition can take many forms; it includes knowledge about when and how to use particular strategies for learning or for problem-solving, [5]. There are generally two components of metacognition: (1) knowledge about cognition and (2) regulation of cognition, [6]. Methodologies to develop

CEEA18; Paper 52

University of British Columbia; June 3-6, $2018 \quad-1$ of $6-$ 
these areas will be researched in this paper and learning patterns will be determined.

A combination of mixed method, qualitative and quantitative methodologies will be used to assess the course's performance, further development, and engagement effectiveness. These methodologies include student surveys, focus group discussion, case studies, ethnography, phenomenology, and statistical analyses.

The extended research question is:

\section{"How can the Classroom Engagement be Improved to Maximize Learning in an Interdisciplinary Dual Faculty Capstone Course?"}

The motivation for this research is to develop an engagement process in an interdisciplinary course to maximize student learning. The literature review was conducted over several months and included Goggle Scholar research, E-Library investigations, and relevant CEEA paper reviews. The problem with the present system is that students work in discipline isolation which does not reflect real life situations. Solutions considered included a multidisciplinary program as well as the dual faculty capstone approach. The mixed methodologies that will be used to analyze student engagement are qualitative as well as quantitative approaches. This research will enable Engineering and Architecture students to work effectively and efficiently together.

These efforts highlight the development of a capstone engineering design course from a multidisciplinary engineering program to an interdisciplinary Engineering and Architecture dual faculty offering the evolution of which was presented in 2016 [9] and 2017 [10] papers at previous CEEA's. After collaboration with Faculty of Architecture representatives, the interdisciplinary course was launched in January, 2018. So far, here are some of the course elements that were agreed upon and have been implemented:

- As the course case study project, the Architecture representative named an actual boutique hotel renovation, which is located in a large National Historic Site

- Sixteen (16) Mechanical Engineering students and four (4) Architecture students enrolled in the course

- The course outline and schedule were collaboratively developed and include: classes held late afternoons Tuesdays, and Wednesdays, with Thursday afternoon set aside for the odd site visit, course deliverables are Research Phase I-Concept Definition Report, Schematic Design Phase
II Report, and an overall compiled Final Report Phase III and presentations

- Four (4) student teams, have been set up, each having an Architectural student

- Areas of investigation for each Team include the following categories: building envelope, heating ventilating and air conditioning (HVAC), structural remediation renovations, and new structural elements design

- Class site visits have taken place where students had an opportunity to experience the building full scale, and verify building components

- External consultants, contractors, and building experts delivered relevant lectures on how the new hotel is designed

- Some of the guest lecturers who have already presented include: a Building Code and Fire Code expert, an HVAC professor, a City of Winnipeg Heritage Director, an outside structural engineer, an outside mechanical engineer, and a Sustainable Development professor

- Existing AutoCAD drawings of the new hotel and renderings of a conceptual design had been made available to and reviewed by the class

- The four (4) student Teams have researched their specific design topic, developed their design concepts, participated in Phase I, II, and III oral presentations, and submitted their Phase I, II, and III reports

\section{BACKGROUND}

We decided to take an innovative and creative approach to this research. Rather than team with an outside industry development focus group, we decided to develop a holistic course with the Faculty of Architecture. This approach is facilitated by the Dean of Engineering who also serves as the Dean of the Faculty of Architecture, and supports an Engineering/ Architectural interdisciplinary dual faculty capstone initiative/strategy.

For the purpose of this paper, a capstone course is defined as "...a project-based learning experience that involves engineering practice through a significant design project whereby student teams meet specific client needs through a creative, iterative, and open-ended design process" [8].

\section{METHODOLOGY}


Besides the research conducted for the CEEA 2016 and 2017 paper submissions, in accordance with The University of Manitoba policies, applications have been made to the Research Ethics Board as well as the Survey Review Committee. To protect the rights and welfare of human participants in research studies conducted at, or under the auspices of The University of Manitoba, prior ethics review and approval is required by a Research Ethics Board (REB), [7]. In addition, the purpose of the Survey Review Committee is to review proposed surveys, focus groups, and interviews of students, faculty, staff, and alumni to assess quality, timing, adherence to privacy legislation, and to evaluate the usefulness and applicability of them in achieving The University of Manitoba's strategic objectives.

The methodologies that will be used to develop, implement, and evaluate the Engineering and Architecture capstone course include a mixed method of qualitative and quantitative analyses.

Specifically, during the 2018 winter session and at the end of the term Engineering and Architecture student Ikert Scale surveys will be conducted. The results of the questionnaire will be compared and contrasted to discover how effectively students engaged and learned, whether their personal course goals were achieved and what could be adjusted to accommodate a better learning environment from a metacognitive engagement perspective. For comparative purposes, an additional survey will be performed on undergraduate technology and ethics course students to determine if teaching, engagement, and learning techniques from either course could be applied in the other course to make the teaching more meaningful. In addition, the learning environment will be quantified to enable students to learn at a metacognitive level and achieve their maximum learning experience. The same survey will be given to all three classes, and is shown in Appendix 1, Interdisciplinary Engineering and Architecture Capstone Experience Pilot Course Evaluation Performance Survey. The surveys are structured to determine if students perceive that they have acquired the CEAB attributes and reached a maximum level of engagement as a result of taking the course. The survey has been structured, and set up to facilitate qualitative and quantitative statistical analyses.

Because unbiased research can be performed on students in an unrelated course, a case study analysis will be conducted in a graduate course in engineering design philosophy. One of the case study research question will be "How can the successful teaching techniques of a matured graduate course be applied to an undergraduate multidisciplinary/dual faculty course?" Further research questions will be developed and presented in the next paper.

Peer and self-evaluations will also be employed as a methodology to determine and assess further course development strategies. See Appendix 2, Eng/Arch Interdisciplinary and Dual Faculty Capstone Course Peer Evaluation Winter 2018. Students with low peer reviews will be identified and engagement trends determined by focus group techniques to provide a better learning environment. This process is used to confirm that group members are sharing the work load to maximize Team learning. Peer and self-evaluation results will be cross checked with the performance survey data to verify engagement.

Students will also provide weekly reflective learnings, which will be reviewed and general trends noted. See Appendix3, Eng/Arch Interdisciplinary and Dual Faculty Capstone Course Reflective Learning. These trends will provide student feedback on their engagement, learning and allow the instructors to communicate with students in a nonthreatening environment. Student suggestions on the course delivery will be recorded and implemented.

\section{FINDINGS}

Since this paper is focusing on how the extended engineering and architecture course will be developed, the findings presented here are brief, and a more detailed analysis will be presented in a later paper after the research is completed. Other aspects that will be investigated as well are: encouraging other engineering disciplines to register for the program; opening up the course to business and management faculties, and; applying "green building" design, "net zero energy" requirements, and LEEDS criteria. In addition, the notion of "transdisciplinary" skills will be reviewed to widen the learning experiences.

Lessons learned from piloting the Interdisciplinary Dual Faculty Capstone course include the following:

- The course could become a mandatory Architectural requirement

- The reflective learning was worthwhile and provided opportunities for the teaching staff to communicate with individual students and teams

- Next year's course could include a seven story condominium design project

- Teams need to be better guided by a more detailed deliverable structure

- The guest speaker/lecture process was excellent and should be included next winter 
- Architectural creativity must be encouraged and shared with engineering students

- A Team building workshop should be introduced at the beginning of the course to promote communications

- Architectural and engineering students experienced each other's cultures and worked through the differences

- Students experienced how to understand, interpret, and apply building codes and technical guidelines

The success of this pilot offering can be summed by the following reflections of an Architect student and an Engineering student:

“... I think the most valuable part of this class was the interaction between the disciplines, as (at least in my group) I felt we both pushed each other outside of our comfort zones and gave each other new tools to use in the future. I am not sure the exact perception engineering students have of architecture, but I hope I was able to help them understand the scope of the job and that it is more involved than just aesthetics."

And;

“... Working together as engineering and architectural students has become more harmonious as we have learned each others strong points and been able to exercise those strengths. Integrating the work between the two faculties was truly a unique experience and the team is excited to see what our final deliverable has in store."

\section{NEXT STEPS}

The next steps in this research process are to obtain Research Ethics Board approval, complete the surveys, and focus group analyzes. This course will be offered in the 2019 winter session and the above lessons learned will be applied to make the course a more meaningful. Engineering and Architectural education component.

\section{CONCLUSIONS}

This paper has focused on how an Interdisciplinary Engineering and Architectural capstone course has been piloted and launched for the Faculty of Engineering and the Faculty of Architecture at The University of Manitoba in order to create a more meaningful capstone design experience for undergraduate students, better prepare them for professional employment, enhance compliance with the CEAB Graduate Attributes requirements, and investigate whether an engaging level of consciousness could be developed for students to maximize learning.

\section{Acknowledgements}

The authors would like to thank the following individuals:

Douglas Ruth, P. Eng., Ph.D.

Jillian Seniuk Cicek, Ph.D. Candidate

Dr. Marcia Friesen, Associate Dean Faculty of Engineering

Dr. Jonathon Beddoes, Dean Faculty of Engineering and Faculty of Architecture

Dr. Robert D. Renaud, Head Department of Educational Administration Foundations and Psychology

Dr. Robert Derksen, Associate Professor, Mechanical Engineering

Dr. Eric Bibeau, associate Professor, Mechanical Engineering

Dr. John Frye, Engineer in Residence, Civil Engineering

Neil Minuk, MAA, Associate Professor, Faculty of Architecture

Dr. Carlos Rueda, Head Department Faculty of Architecture

\section{References}

[1]Aditya Johri, and Barbara M. Olds, The Cambridge Handbook of Engineering Education. New York, NY: Cambridge University Press, 2014, pp. \{ISBN:

[2] Engineers Canada (2012), Canadian Accreditation Engineering Board Accreditation Criteria and Procedures

[3] http://en Wikipedia.org/wiki/Altered level of consciousness\#Glasgow Coma Scale, December 24, 2017017

[4] Maura Borrego and Lynita K. Newswander, "Characteristics of successful cross-discipline engineering education collaborations," Journal of Engineering Education, vol. 97, no. 2, pp. 123-134, 2008.

[5] Metcalfe, J., \& Shimamura, A. P., "Metacognition: knowing about knowing" Cambridge, MA: MIT Press, 1994

[6] Schraw, Gregory, "Promoting general metacognitive awareness". Instructional Science. 26: 113-125,

doi:10.1023/A:1003044231033,(1998)

[7] http:// Umanitoba.ca/admin/oia/survey/6256.html, May 4 2017

[8] $\mathrm{U}$ of $\mathrm{T}$ definition for capstone https://www.mie.utoronto.ca/undergrad/capstone downloaded May 2, 2016

[9] W.C.D. DeGagne, and Paul Labossiere, "Development and Implementation of a Cross Discipline Capstone Design Experience at The University of Manitoba" in Proc. CEEA Canadian Engineering Education Conf., CEEC16, (ed.) (Dalhousie University, Halifax, Nova Scotia; 19-22 June 2016), [10] W.C.D. DeGagne, and Paul Labossiere, "Design of a Consistent Interdisciplinary and Dual Faculty Capstone Experience at The University of Manitoba Cross Discipline Capstone Design Experience at The University of Manitoba" in 
Proc. 2018 Canadian Engineering Education Association (CEEA18) Conf.

Proc. CEEA Canadian Engineering Education Conf., CEEA17, (ed.) (University of Toronto, Toronto Ontario; 3-6 June 2017), http://www.umanitoba.ca/research/orec/ethics/human_ethics_in dex.html May 4, 2017

\section{APPENDIX 1: INTERDISCIPLINARY ENGINEERING AND ARCHITECTURE CAPSTONE EXPERIENCE PILOT COURSE EVALUATION PERFORMANACE SURVEY}

For brevity, the preamble which contains research purpose, ethics approval requirements, survey processing guidelines, and additional instructions, has been omitted here.

Survey Instructions: Please circle the letter or letters of your choice or choices.

1. What year of the Engineering program are you currently enrolled? 1, 2, 3, 4, +5

2. Are you an Engineering or Architecture Student?

3. Have you previously taken any of the following discipline specific capstone courses?

(Yes/No)

a. MECH 4860 Engineering Design

b. ECE 4600 Group Design Project

c. CIVL 4590 Capstone Design Project

d. BIOE 4580 Design Trilogy II

e. BIOE 4580 Design Trilogy III;

4. Would you consider taking an interdisciplinary capstone course?

Never/Not Likely; Don't Know; Likely/Definitely

5. On a scale of 1 to 5,1 being not effectively to 5 being most effectively, I learn more effectively and efficiently from Researching on your own

6. On a scale of 1 to 5,1 being not effectively to 5 being most effectively, I learn more effectively and efficiently from Researching in teams

7. On a scale of 1 to 5,1 being not effectively to 5 being most effectively, I learn more effectively and efficiently from completing assignments on the material covered

8. On a scale of 1 to 5,1 being not effectively to 5 being most effectively, I learn more effectively and efficiently from giving lectures to fellow class mates

9. On a scale of 1 to 5,1 being not effectively to 5 being most effectively, I learn more effectively and efficiently from working with industry sponsors

10. On a scale of 1 to 5,1 being not effectively to 5 being most effectively, I learn more effectively and efficiently from open ended discussion lectures

11. On a scale of 1 to 5,1 being not effectively to 5 being most effectively, for students who have already completed an interdisciplinary capstone design course, I was better able to solve complex engineering/Architectural problems based on the course learnings.

12. On a scale of 1 to 5,1 being not effectively to 5 being most effectively, I learn more effectively and efficiently for students who have already completed an interdisciplinary capstone design course, I was better able to design solutions for complex, open-ended engineering problems with appropriate attention to economic, environmental, cultural, and societal considerations based on the course learnings.

13. On a scale of 1 to 5,1 being not effectively to 5 being most effectively, I learned more effectively and efficiently for students who have already completed an interdisciplinary capstone design course, were you better able to communicate complex engineering concepts within the profession and with society at large.

14. On a scale of 1 to 5,1 being not effectively to 5 being most effectively, I will learn more effectively and efficiently, for students who plan to complete the interdisciplinary capstone course, I expect that completing the course will give me an ability to solve complex engineering/Architectural problems based on the course learning.

15. On a scale of 1 to 5,1 being not effectively to 5 being most effectively, I will learn more effectively and efficiently for students who plan to complete the interdisciplinary capstone course, I expect that completing the course will give me an ability to design solutions for complex, open-ended engineering/Architectural problems with appropriate attention to economic, environmental, cultural, and societal considerations based on the course learnings.

Never/Not Likely; Don't Know; Likely/Definitely

16. On a scale of 1 to 5,1 being not effectively to 5 being most effectively, I will learn more effectively and efficiently for students who plan to complete an interdisciplinary capstone design course, do you expect that completing the course will give me ability to communicate complex engineering concepts within the profession and with society at large.

17. What year of the Architecture program are you currently enrolled? Graduate year 1, Graduate year 2, or Graduate year 3

18. On a scale of 1 to 5,1 being never, to 5 being always I pre-read the lesson to maximize my learning:

19. On a scale of 1 to 5,1 being never, to 5 being always, I review the $\mathrm{D} 2 \mathrm{~L}$ website for new postings before classes.

20. On a scale of 1 to 5,1 being never, to 5 being always, I prepare a list of questions from my research on information I did not immediately understand to ask in class.

21. On a scale of 1 to 5,1 being never, to 5 being always, during the lecture I focus on being engage in the class learning. 
Proc. 2018 Canadian Engineering Education Association (CEEA18) Conf.

22. On a scale of 1 to 5,1 being never, to 5 being always, I put my cellular phone on vibrate before classes

23. On a scale of 1 to 5,1 being never, to 5 being always, I engaged and focus on the class learning.

24. Have you ever taken course outside your home faculty before? Yes/No

25 . If yes, on a scale of 1 to 5,1 being never, to 5 very much, I learned from a different cultural experience.

26. If yes, to question 25 , on a scale of 1 to 5,1 being never, to 5 being very much, I learned how to function in that different cultural experience.

27. If yes, to question 26, on a scale of 1 to 5,1 being never, to 5 being very much, I learned how to function in that different cultural.

APPENDIX 2: ENG/ARCH INTERDISCIPLINARY AND DUAL FACULTY CAPSTONE COURSE PEER EVALUATION - WINTER 2018

In the space below, honestly evaluate the other members of your class using the provided criteria and ranking system. In the case where you feel a group member's contribution was unsatisfactory, please provide an explanation in the comments.

Evaluations are to be submitted by email to Bill DeGagne and the TAs no later than Midnight on Friday, April XX, 2018.

Evaluator's Name: Class Member 1:

1. Carried a fair share of the workload

2. Completed all assigned tasks with a high degree of quality

3. Completed all assigned tasks within a timely manner

4. Was overall pleasant/easy to work with

5. Was overall a valuable contributing member Additional comments (optional):

\section{APPENDIX 3: ENG/ARCH INTERDISCIPLINARY AND DUAL FACULTY CAPSTONE COURSE REFLECTIVE LEARNING - WINTER 2018}

Students will submit Reflective Learning (RL) comments. Each should contain your personal reflection, showing your understanding and critical thinking of one or more of the following:

- How the specific week(s) course work applies to you, and lessons learned

- How the week(s) course work could be adapted to your work or personal context

- How the week(s) course work may be relevant to you or your specific field.

Whatever you choose to write should contain some depth of thought - a very personal reflection. Each RL should be concise and between 100 to 150 words. Reflective learnings longer than 150 words may not be marked.

CEEA18; Paper 52

University of British Columbia; June 3-6, $2018 \quad-6$ of $6-$ 